\title{
ACESSIBILIDADE AOS EDIFÍCIOS E SERVIÇOS PÚBLICOS
}

\author{
OLIVEIRA, Aíla Seguin Dias Aguiar de (1) \\ (1) Tribunal de Contas do Estado do Pará, M.Sc. \\ e-mail:ailaseguin@hotmail.com
}

\begin{abstract}
RESUMO
O uso do espaço e edifício público é um direito de todos. Porém, a maioria desses espaços é projetada desconsiderando a diversidade humana, dificultando a inclusão e participação de todos os seus possíveis usuários, tais como as pessoas com deficiência e mobilidade reduzida. Este trabalho teve como objetivo realizar uma avaliação quanto às condições de acessibilidade em edifícios de responsabilidade do Governo do Estado do Pará. A análise foi realizada a partir de Questionários e Vistorias Técnicas, os quais forneceram informações para que fossem elaboradas recomendações técnicas com intuito de sanar os problemas encontrados.
\end{abstract}

Palavras chave: acessibilidade; edifícios públicos; pessoas com deficiência.

\begin{abstract}
The use of space and public building is everyone's right. However, most of these spaces are designed disregarding human diversity, making it difficult to include and participate in all possible users, such as people with disabilities and reduced mobility. The objective of this study was to evaluate the accessibility conditions in buildings under the responsibility of the Government of the State of Pará. The analysis was based on Questionnaires and Technical Visits, which provided information for the elaboration of technical recommendations to heal the problems encountered
\end{abstract}

Keywords: accessibility; public buildins; people with disabilities.

\section{INTRODUÇÃO}

O direito de ir e vir, e de igualdade a todos os cidadãos estão garantidos na Constituição Brasileira desde 1988, no entanto foi necessária a criação de leis e normas específicas, a fim de contribuir para a participação significativa das pessoas com deficiência na sociedade e garantir a efetiva acessibilidade nos espaços físicos e, em especial, nos edifícios de uso público.

A fim de avaliar as condições de acessibilidade das pessoas com deficiência ou mobilidade reduzida em edifícios utilizados por órgãos ou entidades da administração pública do Estado do Pará, bem como aos serviços disponibilizados às pessoas com deficiência no interior das unidades de atendimento, foram realizadas vistorias técnicas baseadas na legislação específica vigente.

Para tanto, foram utilizadas planilhas que servem como um check list, de forma a avaliar as condições de acessibilidade, as quais foram resultados da dissertação de mestrado desta pesquisadora, e a aplicação de questionários para os gestores dos órgãos, com intuito de conhecer as condições dos serviços de atendimento das pessoas com deficiência ou mobilidade reduzida. O objetivo deste trabalho é desenvolver laudos técnicos que 


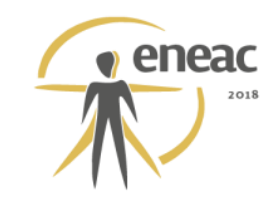

identifiquem, principalmente, os aspectos negativos quanto à acessibilidade nos edifícios analisados, e por fim, elaborar recomendações para solucionar os problemas encontrados.

\section{FUNDAMENTAÇÃO TEÓRICA}

\subsection{Acessibilidade}

O termo acessibilidade é bastante abrangente e envolve inúmeros conceitos e definições. Para Dischinger (2012), a acessibilidade não está apenas ligada a fatores físico-espaciais, mas também a aspectos políticos, sociais e culturais, que influem na realização das atividades desejadas.

A acessibilidade refere-se à possibilidade de participação das pessoas na sociedade em condições de igualdade e sem discriminação, sendo uma das condições para atingir a inclusão social. Conforme Duarte (2005), a acessibilidade do espaço construído não deve ser compreendida como um conjunto de medidas que favoreceriam apenas às pessoas com deficiência, mas sim medidas técnico- sociais destinadas a acolher todos os usuários em potencial. Para isso, é necessário garantir total acesso aos mais variados locais e atividades, eliminando as diversas barreiras existentes que comprometem a participação de todos.

Portanto, a acessibilidade é a possibilidade de compreensão da função, da organização e das relações espaciais que o ambiente estabelece, e a participação das atividades que ali ocorrem, fazendo uso dos equipamentos disponíveis com segurança e autonomia (BINS ELY et al, 2001).

\subsection{Componentes de Acessibilidade}

A fim de compreender melhor as questões referentes à acessibilidade de pessoas que possuem algum tipo de restrição, Dischinger (2012) identificaram quatro componentes, a partir dos quais é possível avaliar-se o nível de acessibilidade do ambiente construído. São eles: orientação, deslocamento, uso e comunicação.

Orientação: condição de compreensão do espaço (legibilidade espacial) a partir de sua configuração arquitetônica e da sua organização funcional. É a possibilidade de distinguir o local onde se está, e o percurso que se deve fazer para chegar a um determinado destino, a partir de informação arquitetônica e suportes informativos (placas, letreiros, sinais, mapas).

Cabe ressaltar que as informações adicionais devem ser acessíveis a todos, como textos em Braille para o deficiente visual e pictogramas para analfabetos e crianças. A ausência destas informações gera situações constrangedoras, pois acentua as restrições, causando exclusão e reduzindo a acessibilidade do ambiente.

Deslocamento: condição de movimento nos percursos horizontais e verticais e sua continuidade. É a possibilidade de deslocar-se de forma independente em percursos livres de obstáculos, que ofereçam conforto e segurança ao usuário. Este componente quando não aplicado gera dificuldades principalmente às pessoas com restrições físico-motoras. Por exemplo, a ausência de rampa ou algum dispositivo eletromecânico que possibilite a circulação de um usuário de cadeira de rodas dentro de ambientes com desníveis como cinemas e teatros. 
Uso: condição que possibilita a utilização dos equipamentos e a participação nas atividades fins. Os equipamentos devem ser acessíveis a todos os usuários e manuseados com segurança, conforto e autonomia. Pessoas com restrições físico-motoras (ausência de força física, coordenação motora, precisão ou mobilidade) possuem limitações para utilizar certos equipamentos existentes no ambiente, como por exemplo, um cadeirante alcançar uma estante de livros com altura inadequada. $O$ usuário com deficiência visual, por exemplo, possui dificuldade para visitar uma exposição de arte, devido à ausência de dispositivos de áudiodescrição ou textos em Braille, que informe sobre as obras expostas e as atividades existentes.

Comunicação: condição de troca e intercâmbio entre pessoas e entre pessoas e equipamentos de tecnologia assistiva (como terminais de computadores e telefones com mensagens de texto), que permitam o ingresso e uso do ambiente. $\mathrm{Na}$ ausência deste componente no ambiente, os usuários com restrições auditivas e restrições cognitivas são os que mais enfrentam dificuldades, como por exemplo, a ausência de funcionários capacitados (intérpretes de Libras) para o atendimento de usuários surdos nos centros culturais.

\subsection{Dispositivos Legais}

Consta na Constituição Federal de 1988, que os fundamentos da nação são promover a dignidade da pessoa humana e garantir o exercício da cidadania para que não haja desigualdades sociais e sejam eliminados quaisquer preconceitos ou descriminações. Isto significa conceder a todos, inclusive as pessoas com deficiência, direitos sociais à educação, à saúde, ao trabalho, ao lazer e à segurança.

O pleno exercício dos direitos às pessoas com deficiência, foi ratificado pela Lei $\mathbf{n} \times \mathbf{7 . 8 5 3 / 8 9}$, que transferiu para Estados e Municípios a responsabilidade pela adoção de normas que eliminem as barreiras de acesso às edificações e aos espaços urbanos.

Também em nível federal, foi aprovado o Decreto no 5.296 de 2 de dezembro de 2004, que estabelece normas gerais e critérios básicos para a promoção da acessibilidade das pessoas com deficiência ou com mobilidade reduzida, e dá outras providências.

O Decreto institui que, para a aprovação e licenciamento de projetos arquitetônicos e urbanísticos, a concepção e implantação devem atender os princípios do desenho universal, tendo como referenciais básicos as normas técnicas de acessibilidade da ABNT.

A fim de suprir uma carência de referenciais técnicos a respeito da questão da acessibilidade, a Associação Brasileira de Normas Técnicas - ABNT elaborou, entre outras, a NBR 9050- "Acessibilidade a edificações, mobiliário, espaços e equipamentos urbanos", revisada em 2015, e a NBR 16537/2016 - "Sinalização tátil no piso: Diretrizes para elaboração de projetos e instalação". As normas atendem a preceitos de desenho universal, e devem ser aplicadas a todos os projetos que virem a ser elaborados, construídos, bem como as reformas e ampliações de edificações e equipamentos já existentes.

Cabe ressaltar também que em 2015 foi regulamentada a Lei № 13.146 que institui a Lei Brasileira de Inclusão da Pessoa com Deficiência (Estatuto da Pessoa com Deficiência), onde define acessibilidade como a possibilidade e condição de alcance para utilização, com segurança e autonomia, de espaços, mobiliários, equipamentos urbanos, edificações, transportes, informação e comunicação, inclusive seus sistemas e tecnologias, bem como de outros serviços e instalações abertos ao público, de uso público ou privados de uso coletivo, tanto na zona urbana como na rural, por pessoa com deficiência ou com mobilidade reduzida. 


\section{ESTUDO DE CASOS}

Este trabalho se desenvolve a partir da realização de vistorias técnicas, ocorridas em novembro e dezembro de 2012, em oito edifícios de uso público, sendo estes dos respectivos órgãos e entidades:

- Secretaria de Estado Justiça e Direitos Humanos - SEJUDH (02 edifícios);

- Secretaria de Estado de Assistência Social - SEAS (02 edifícios);

- Defensoria Pública do Estado do Pará (01 edifício);

- Instituto de Assistência aos Servidores do Estado do Pará - IASEP (02 edifícios);

- Instituto de Gestão Previdenciária do Estado do Pará - IGEPREV (01 edifício).

Cabe ressaltar que os mesmos foram escolhidos por receberem, diariamente, uma demanda significativa de público, inclusive o atendimento de segurados como é o caso do Instituto de Assistência aos Servidores do Estado do Pará, e por estarem localizados na capital do Estado, Belém.

\section{MÉTODOS}

A estratégia metodológica escolhida constituiu na realização de vistorias técnicas in loco e no envio de questionário para os gestores dos órgãos e entidades. Durante as vistorias foram aplicadas Planilhas de Avaliação e realizados os levantamentos técnico e fotográfico dos edifícios.

\section{RESULTADOS}

Após a aplicação das planilhas, foram elaborados relatórios técnicos, com intuito de encaminhar para os responsáveis pelos órgãos e entidades, para que os mesmos possam sanar as irregularidades encontradas de forma legal e rápida.

Quanto aos aspectos encontrados podemos classificá-los conforme os quatro componentes da acessibilidade.

Com relação à orientação observou-se, por exemplo, que em todos os edifícios, existe uma carência de suportes informativos (visuais e táteis) desde os passeios até o interior dos mesmos (Figura 1); ausência de sinalização tátil no piso; a ausência de anúncio verbalizado indicando a chamada das senhas para pessoas com deficiência visual (figura 2); ausência de piso tátil alerta em frente às portas dos elevadores, início e término de rampas e escadas (Figura 3); inexistência de mapas táteis. Nos elevadores foi possível detectar a ausência de sinalização em Braille na botoeira e do anúncio verbal indicando cada parada do mesmo, entre outros aspectos, conforme demostrado nas figuras abaixo. 
Figura 1 - Ausência de sinalização tátil nas portas.

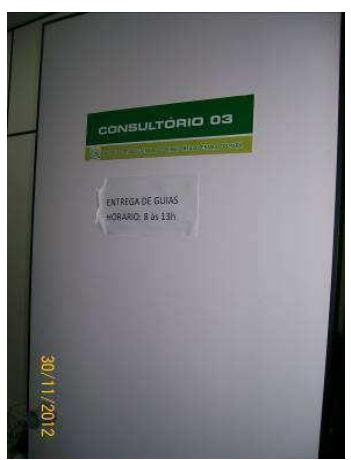

Fonte: autora

Figura 2 - Ausência de senha verbalizada para orientar a pessoa com deficiência visual.

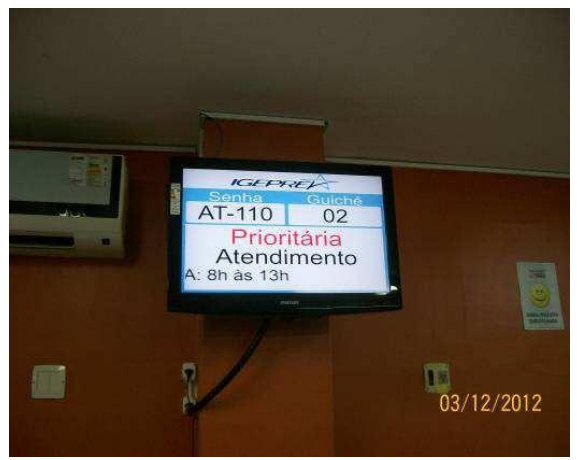

Fonte: autora

Figura 3 - Ausência de piso tátil no início e término de escadas.

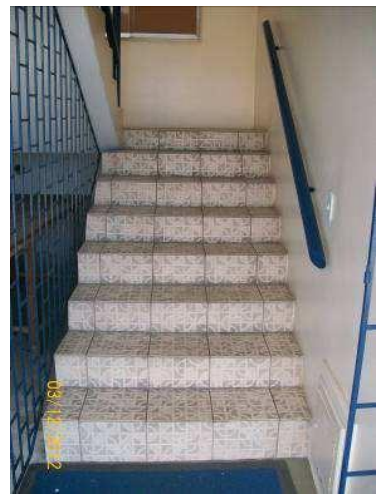

Fonte: autora

Com relação ao deslocamento, observou-se que as calçadas em frente aos órgãos encontram-se deterioradas com diversos desníveis e elementos que obstruem a circulação. Constatou-se a presença de veículo do próprio órgão estacionado sobre a calçada (Figura 4). Presença de desníveis nas entradas principais dos edifícios (Figura 5). Observou-se também a existência de obstáculos ao longo das rampas, além das mesmas possuírem largura e inclinação inadequadas (Figura 6). Foi possível constatar a presença de capachos soltos e rasgados, além de elementos suspensos sobre a circulação. Em todos os edifícios e 
layout dos móveis prejudica, ou até mesmo, impede a circulação de uma cadeira de rodas (Figura 7).

Figura 4 - Veículo do órgão estacionado sobre a calçada.

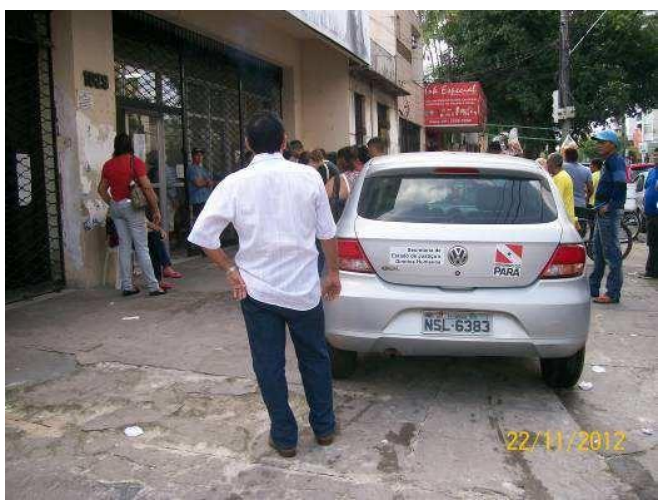

Fonte: autora

Figura 5 - Desnível na soleira da entrada principal.

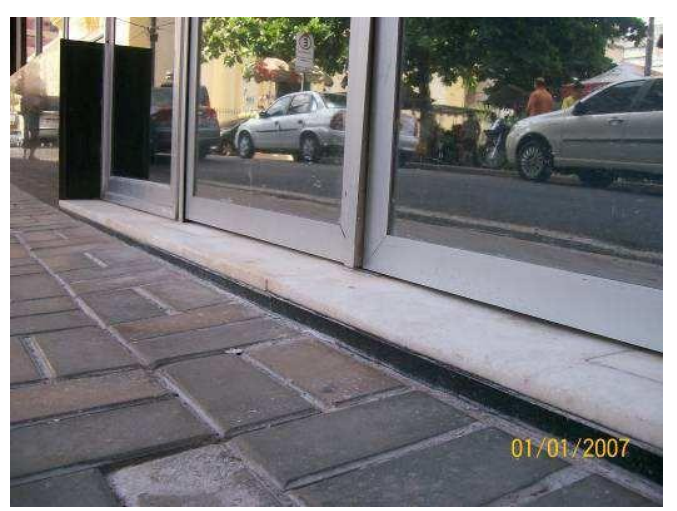

Fonte: autora

Figura 6 - Rampa inadequada.

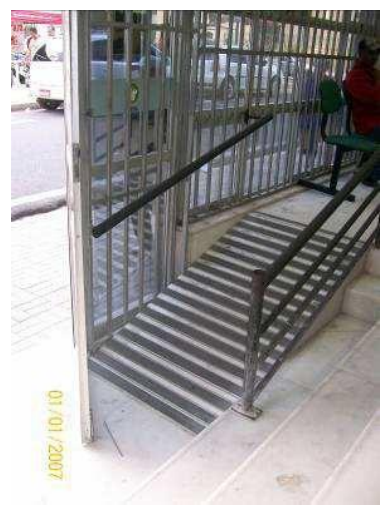

Fonte: autora 
Figura 7 - Sala de atendimento com layout de impede a circulação de uma cadeira de rodas.

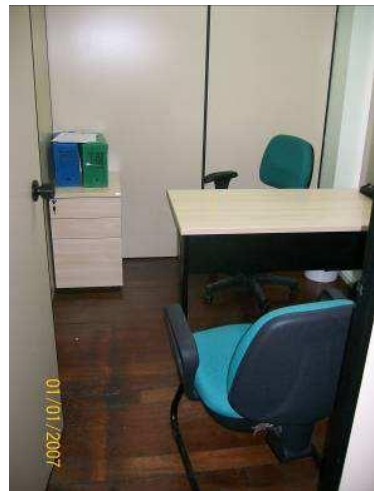

Fonte: autora

Quanto ao uso dos equipamentos e elementos existentes nos edifícios, observou-se, por exemplo, a ausência de balcões de atendimento com altura adequada para o uso de cadeirantes e pessoas de baixa estatura (Figura 8). Constatou-se também a ausência de espaço para cadeira de rodas e assentos para obesos nas salas de espera (Figura 9). Presença de relógio de ponto localizado no patamar da escada (Figura 10). Sanitários para pessoas com deficiência, quando abertos, possuindo diversas irregularidades, tais como a altura inadequada do vaso sanitário e barras de apoio, maçaneta tipo bola, portas abrindo sobre a circulação (Figura 11). Rolo de senhas com altura inadequada (Figura 12).

Figura 8 - Balcão com dimensões inadequadas.

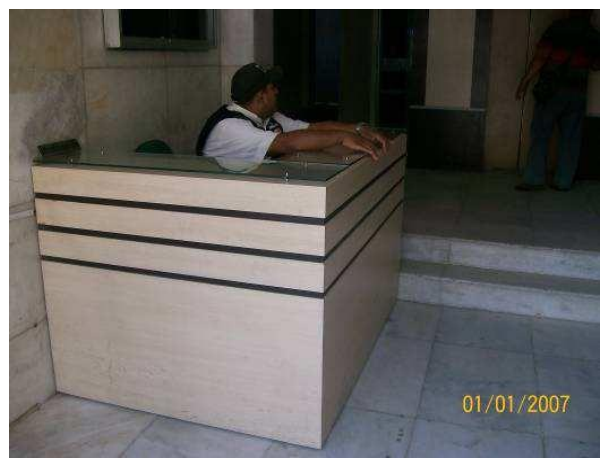

Fonte: autora

Figura 9 - Ausência de espaços para cadeiras de rodas e assentos preferenciais.

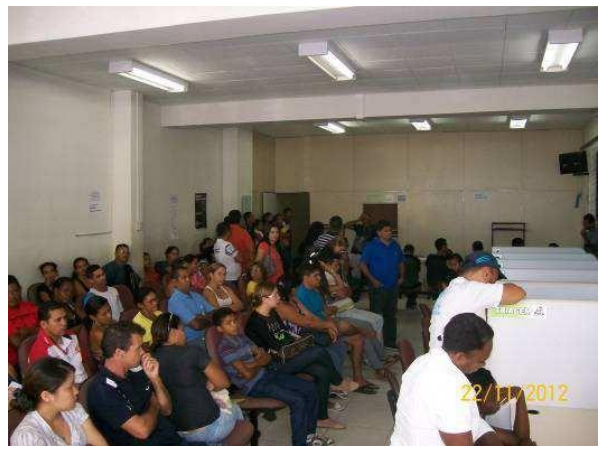

Fonte: autora 
Figura 10 - Relógio de ponto alto e localizado no patamar da escada.

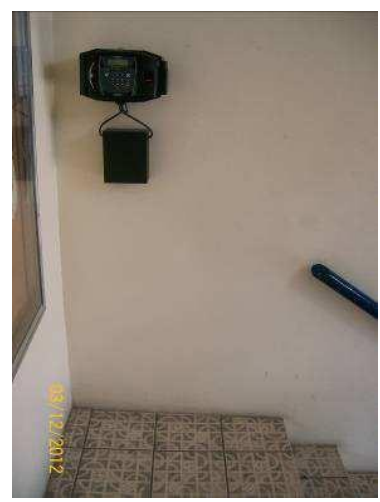

Fonte: autora

Figura 11 - Porta do sanitário acessível abrindo sobre a circulação.

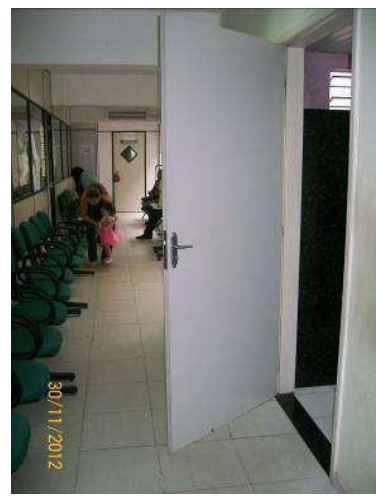

Fonte: autora

Figura 12 - Rolo de senha com altura inadequada.

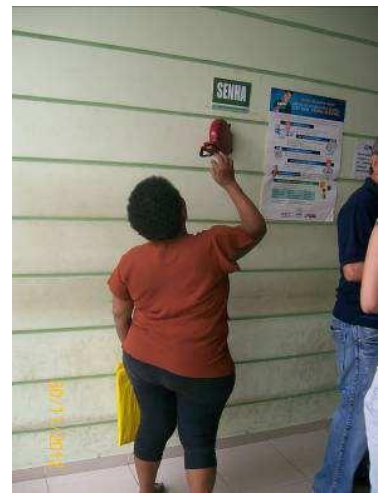

Fonte: autora

Quanto à comunicação, foram constatados problemas como a ausência de intérpretes de LIBRAS (Figura 13), e a ausência de algum tipo de tecnologia assistiva (terminal de computador, por exemplo) que possibilitasse a comunicação do usuário, em especial o com deficiência auditiva e visual, com os funcionários do órgão. 
Figura 13 - Ausência de intérprete de LIBRAS no atendimento ao público.

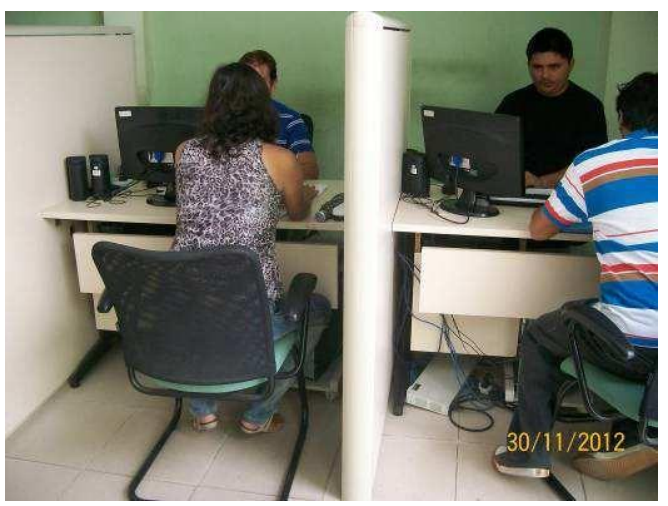

Fonte: autora

Quanto ao resultado da aplicação dos questionários para os gestores dos órgãos e entidades analisadas, constatou-se que 03 (três) dos 05 (cinco) órgãos alegaram ausência de engenheiros e arquitetos capacitados para realizar as adaptações necessárias e a dificuldade de adaptar seus prédios, pois alguns são alugados. Também foram citados problemas como a falta de treinamento dos profissionais por parte do Estado, a ausência de alocação de verba específica para acessibilidade e, até mesmo, a falta de conhecimento por, por parte do gestor, da necessidade de realizar as adaptações.

\section{CONCLUSÃO}

Promover a acessibilidade é fundamental para que as pessoas, independentemente de suas habilidades e restrições, exerçam o seu direito de ir e vir, ao lazer, a educação, a saúde, enfim exerçam seus direitos como cidadão.

Porém, apesar da existência de inúmeros dispositivos legais, foi possível detectar, a partir da aplicação das Planilhas de Avaliação e dos questionários, que os edifícios públicos, na sua grande maioria, ainda não garantem a efetiva acessibilidade às pessoas com alguma deficiência ou mobilidade reduzida.

Diante disto, a fim de resolver os problemas encontrados, acredita-se que algumas soluções devem ser realizadas o quanto antes, por parte do Governo do Estado, tais como: a realização de diagnóstico da situação real de todos os imóveis, próprios e alugados, a fim de definir metas progressivas para sanar as carências existentes; possibilitar a criação de classificação orçamentária específica para contemplar os gastos em acessibilidade e, principalmente, capacitar os arquitetos e engenheiros servidores para que possam desenvolver e executar projetos acessíveis, contribuindo para a inclusão social e a participação de todas as pessoas nas atividades realizadas em edifícios e espaços públicos.

\section{REFERÊNCIAS BIBLIOGRÁFICAS}

ABNT - Associação Brasileira de Normas Técnicas: NBR 9050: Acessibilidade a edificações, mobiliário, espaço e equipamentos urbanos. Rio de Janeiro, 2015.

ABNT - Associação Brasileira de Normas Técnicas: NBR 16537: Acessibilidade - Sinalização tátil no piso - Diretrizes para elaboração de projetos e instalação. Rio de Janeiro, 2016. 
PET/Arq/ SESu/ UFSC, 2001.

BRASIL. Lei no 13.146, de 6 de julho de 2015. Institui a Lei Brasileira de Inclusão da Pessoa com Deficiência (Estatuto da Pessoa com Deficiência).

BRASIL. Decreto n 5.296 de 2 de dezembro de 2004. Regulamenta as leis n 10.048, de 8 de novembro de 2000 e a n 10.098, de 19 de dezembro de 2000. Estabelece normas gerais e critérios básicos para a promoção de acessibilidade das pessoas com deficiência ou com mobilidade reduzida, e dá outras providências.

BRASIL. Lei no 7.853 de 24 de outubro de 1989. Dispõe sobre o apoio as pessoas portadoras de deficiência, sua integração social, sobre a Coordenadoria Nacional para Integração de Pessoas Portadoras de deficiência. CORDE, 1989.

BRASIL. Senado Federal. Secretaria Geral da Mesa. Constituição Federal de 1988.

DISCHINGER, Marta. Promovendo acessibilidade nos edifícios públicos: Programa de Acessibilidade às Pessoas com Deficiência ou Mobilidade Reduzida nas Edificações de Uso Público / Marta Dischinger, Vera Helena Moro Bins Ely, Sonia Maria Demeda Groisman Piardi. - Florianópolis: MPSC, 2012

DUARTE, Cristiane Rose; COHEN, Regina. Pesquisa e projeto de espaços públicos: rebatimentos e possibilidades de inclusão da diversidade física no planejamento das cidades. In: PROJETAR 2005 - II Seminário sobre Ensino e Pesquisa em Projeto de Arquitetura, 2005, Rio de Janeiro. Anais do II PROJETAR. 2005. 